\title{
Tinjauan pustaka sistematis manajemen pendidikan: Kerangka konseptual dalam meningkatkan kualitas pendidikan era 4.0
}

\author{
Fitri Nur Mahmudah * ${ }^{1}$, Eka Cahya Sari Putra ${ }^{2}$ \\ ${ }^{1}$ Universitas Ahmad Dahlan \\ Jl. Pramuka No.42, Pandeyan, Umbulharjo, Yogyakarta 55161, Indonesia. \\ ${ }^{2}$ Universitas Negeri Yogyakarta \\ Jl. Colombo No. 1, Depok, Sleman, Yogyakarta 55281, Indonesia. \\ * Corresponding Author. Email: fnurmahmudah@gmail.com
}

\section{ARTICLE INFO}

\section{Article History}

Received:

3 August 2020;

Revised:

27 April 2021;

Accepted:

3 May 2021

Available online:

3 May 2021

\section{Keywords}

kerangka konseptual;

kualitas pendidikan;

manajemen

pendidikan;

era 4.0.

conceptual framework; educational quality;

educational

management;

4.0 era.

\begin{abstract}
Tujuan penulisan artikel ini adalah untuk mengetahui program apa saja yang dapat mewujudkan sumber daya manusia (SDM) unggul era 4.0 dan untuk membuat kerangka konseptual baru dalam manajemen pendidikan yang dapat meningkatkan kualitas pendidikan era 4.0. Artikel ini ditulis dengan menggunakan metode literature review dengan pendekatan mapping review. Proses literature review ini dilakukan dengan cara mencari artikel yang relevan, mengevaluasi dengan cara ekstraksi, menganalisis, dan selanjutnya mensintesis. Database yang digunakan dalam pencarian referensi menggunakan JSTOR dan Springer Link. Hasil dari literature review ini adalah bahwa program-program pendidikan yang menunjang adanya revolusi industri 4.0 berkaitan dengan digital transformation pada aspek-aspek manajemen pendidikan. Kerangka konseptual yang dibuat berkaitan dengan aspek manajemen yang meliputi SDM, Kurikulum, Pembelajaran, Pembiayaan, Sarana Prasarana, Humas, dan Kompetensi Lulusan.
\end{abstract}

\begin{abstract}
The purpose of this article writing is to find out what programs can realize superior human resources $(H R)$ of 4.0 era and to create a new conceptual framework in education management that can improve the quality of education in the $4.0 \mathrm{era}$. This article was written using the literature review method with a mapping review approach. The literature review process was carried out by finding relevant articles, evaluating them by extracting, analyzing, and then synthesizing. The database used in searching references was JSTOR and Springer Link. The results of this review literature are that educational programs that support the 4.0 industrial revolution are related to digital transformation in aspects of educational management. The conceptual framework created is related to management aspects which include $H R$, Curriculum, Learning, Financing, Infrastructure Facilities, Public Relations, and Graduates' Competencies.
\end{abstract}

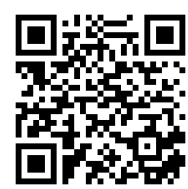

This is an open access article under the CC-BY-SA license.

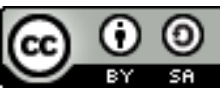

\section{How to cite:}

Mahmudah, F., \& Putra, E. (2021). Tinjauan pustaka sistematis manajemen pendidikan: Kerangka konseptual dalam meningkatkan kualitas pendidikan era 4.0. Jurnal Akuntabilitas Manajemen Pendidikan, 9(1), 43-53. doi:https://doi.org/10.21831/jamp.v9i1.33713 


\section{PENDAHULUAN}

Dunia saat ini telah memasuki era industri 4.0. Perubahan ini tidak dapat dihindari, sehingga perlu penyiapan dari segi sumber daya manusia (SDM) yang memadai agar dapat bersaing dalam skala global. Pada era ini, batas antara manusia, mesin, dan sumber daya lainnya semakin konvergen, sehingga berimbas pada berbagai sektor kehidupan (Lase, 2019, p.29). Sehubungan dengan hal ini, kunci untuk mempersiapkan SDM agar mampu mengikuti perkembangan ini terdapat pada jalur pendidikan (Lee, 2018).

Pendidikan yang diimplementasikan idealnya harus didasarkan atas respon dari kebutuhan industri. Kurikulum yang diterapkan selayaknya mampu membuka akses agar menciptakan SDM yang mampu bersaing, kompetitif, dan produktif. Inovasi teknologi menjadi hal yang wajib ada, karena sangat dibutuhkan dalam era ini. Penyelarasan manusia serta teknologi diharapkan mampu memberikan solusi serta menciptakan inovasi baru, sehingga SDM yang diciptakan pun mampu bersaing di kancah global.

Hasil penelitian yang dilakukan oleh Institute for Management Development (IMD) menunjukkan bahwa daya saing tenaga kerja Indonesia masih tertinggal dibandingkan sejumlah negara ASEAN, seperti Thailand, Mayalsia, dan Singapura. Naiknya ranking Singapura dikarenakan kesuksesan mereka dalam membangun infrastruktur teknologi yang canggih dengan memiliki tenaga kerja terampil, memiliki Undang-Undang Imigrasi yang bersahabat, dan sukses melakukan efisiensi dalam proses pendaftaran usaha.

Menghadapi tantangan yang besar pada era revolusi industri 4.0, pendidikan dituntut untuk dapat mengimbangi perubahan tersebut. Perubahan yang ada bercirikan pemanfaatan teknologi digital dalam proses pembelajaran melalui cyber system yang dilakukan secara berkelanjutan. Akhir dari proses pendidikan itulah yang sebenarnya menjadi tantangan yang ada di Indonesia, yaitu memiliki lulusan yang bermutu, mampu bersaing dengan tuntutan perkembangan era, berkompetensi, serta profesional.

Perlunya adaptasi bagi seluruh komunitas pendidikan ialah agar mampu menangani kondisi yang ada, dan tidak memperumit adanya kesempatan yang tidak digunakan. Pendidikan hanya sebuah komponen, di mana peran utama adalah sumber daya manusianya, sehingga antara pendidik dengan pendidikan memiliki satu kesatuan yang penting dalam menentukan kemajuan bangsa. Bangsa yang maju pasti memiliki sistem pendidikan yang bagus dan dapat diakses oleh semua kalangan tanpa terkecuali.

Inti dari sebuah tantangan revolusi 4.0 bagi pendidikan adalah bagaimana pendidikan dapat menjadi poros yang dapat merubah dan memenuhi everchanging needs sesuai kondisi global. Pendidikan merupakan kunci dan wujud utama dalam meningkatkan kemampuan, mengembangkan diri dalam kehidupan, pemerataan kesempatan dalam pendidikan, dan kesejahteraan hidup.

Melalui berbagai kondisi yang telah disampaikan tersebut, diperlukan sebuah manajemen transisi yang mampu mengelola pendidikan masa revolusi industri 4.0. Manajemen transisi inilah yang menjadi tempat dalam transfer pengetahuan dengan keterampilan yang dibutuhkan oleh tantangan bersama. Tanpa adanya manajemen dalam sebuah pengelolaan transformasi dan transisi, tidak akan pernah terjadi peningkatan kualitas sesuai dengan visi dan misi lembaga pendidikan. Oleh karena itulah urgensi dari literature review ini disusun. Pertanyaan Literature Review (PLR) dalam tinjauan ini adalah sebagai berikut. (1) Program apakah yang dapat mewujudkan SDM unggul era 4.0? (2) Kerangka konseptual manajemen pendidikan seperti apakah yang dapat meningkatkan kualitas pendidikan di era 4.0 ?

\section{METODE}

Metode tinjauan yang digunakan dalam makalah ini adalah a systematic literature review. Tipe review yang digunakan adalah mapping review (Grant \& Booth, 2009, p.94). Proses Literature Review ini dilakukan untuk meninjau dengan kajian sistematis secara transparan untuk mencari artikel-artikel penelitian yang sudah dipublikasikan, mengevaluasi dengan cara ekstraksi, menganalisis, dan selanjutnya langkah terakhir, yaitu melakukan sintesis (Robinson \& Lowe, 2015, p.103). Literature Review ini dilaksanakan sejak September 2019 hingga Januari 2020. 


\section{Article Sources}

Bidang manajemen pendidikan merupakan bidang studi yang sangat luas dengan berbagai aspek wacana dan bidang garapan. Adapun database yang digunakan dalam pencarian artikel adalah JSTOR dan Springer Link, untuk memastikan bahwa sumber data mencerminkan dari dua pertanyaan dalam artikel ini. Alasan menggunakan dua database tersebut dikarenakan keduanya open access dan memudahkan dalam pengunduhan artikel sehingga dapat dipahami secara seksama mengenai manajemen pendidikan era 4.0 untuk meningkatkan kualitas pendidikan, sehingga memunculkan sebuah konsep baru. Selain database tersebut, penulis juga menggunakan chapter book dan buku teks yang relevan dengan topik artikel.

Pencarian awal pada database tersebut menggunakan kata kunci "Educational Management in 4.0 Era" dan menemukan banyak artikel, yaitu hampir ratusan ribu artikel dari berbagai basis data. Oleh karena itu, penulis mempersempit tema dalam pencarian dengan menggunakan kata kunci seperti "curriculum in 4.0 era", "facilities in 4.0 era", "practice in educational management in 4.0 era", "readiness for teacher in 4.0", "readiness for student in 4.0", "education in industry 4.0", "strategy teaching in 4.0", "human resources for readiness in 4.0 era", "framework of managing in industry 4.0", dan "managing educational management model".

\section{Article Selection and Screening}

Pencarian artikel dengan menggunakan basis data JSTOR dan Springer Link pada kata kunci yang telah disebutkan tersebut berjumlah 3.789 artikel. Selanjutnya, artikel tersebut diseleksi dan disaring untuk mendapatkan artikel-artikel yang sesuai dengan literature review ini. Artikel-artikel yang tidak relevan dengan dua pertanyaan literature review diidentifikasi berdasarkan ketidaksesuaian dari hasil dan pembahasan mengenai manajemen pendidikan era 4.0.

Tahapan selection and screening ini dilakukan dengan menganalisis judul artikel, kata kunci, abstrak, latar belakang masalah, pertanyaan penelitian, serta hasil dan pembahasan. Tahapan tersebut menghasilkan 459 artikel untuk selanjutnya dikaji secara mendalam dan dipertimbangkan kembali untuk dilakukan selection and screening. Pada tahapan selanjutnya didapatkan 12 artikel yang telah dipublikasi untuk dipertahankan sebagai bahan literature review, sebagai ulasan dan sintesis lengkap dalam menjawab pertanyaan dalam kajian ini. Artikel yang digunakan dalam pencarian dibatasi pada tahun 2016 - 2020. Perbedaan dalam tahapan pencarian artikel yang digunakan dalam literature review ini disajikan pada Gambar 1, dan artikel yang terpilih disajikan dalam Tabel 1.

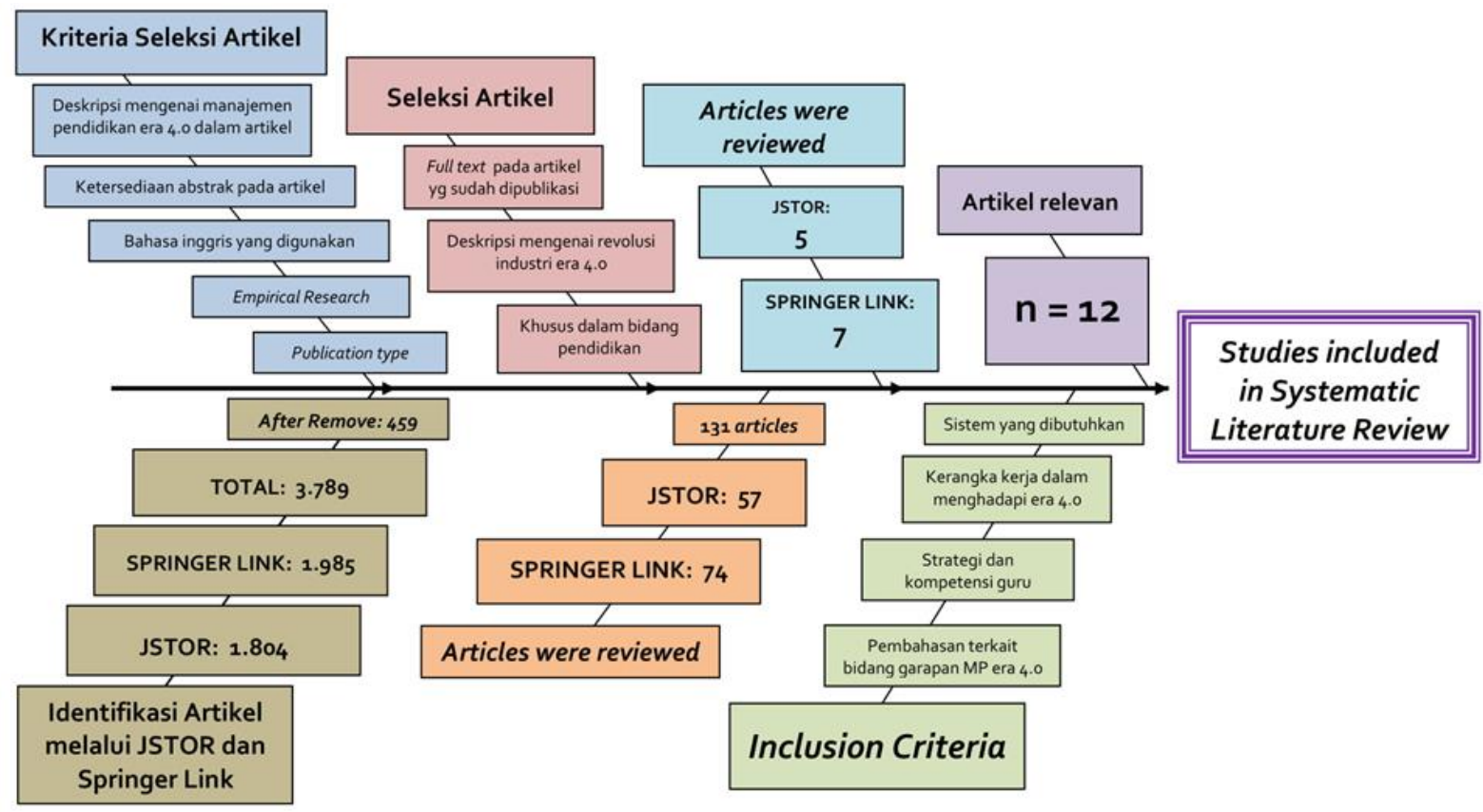

Gambar 1. Tahapan Article Selection and Screening 
Tabel 1. Overview of The Study

\begin{tabular}{cll}
\hline No & \multicolumn{1}{c}{ Study } & \multicolumn{1}{c}{ Method } \\
\hline 1 & Baltaru \& Soysal (2018) & 76l HEIs, Quantitative \\
2 & Chen et al. $(2019)$ & Educators, Evaluating \\
3 & Hoel \& Mason (2018) & Two communities SLEs, Qualitative \\
4 & Khlaif \& Farid (2018) & 30 schools, Qualitative \\
5 & Gleason (2019) & Book Chapter \\
6 & Hazelkorn (2018) & Universities, Qualitative \\
7 & Ahad et al. $(2018)$ & LAS for students in 4.0, Qualitative \\
8 & Chung (2016) & PBL Strategies 4.0 Era, Qualitative \\
9 & Verner et al. $(2018)$ & Students for 4.0 Era, Qualitative \\
10 & Cohen et al. $(2019)$ & Readiness for Industry 4.0, Qualitative \\
11 & Seretny \& Gaur (2020) & MSM Model in 4.0 Era, Qualitative \\
12 & Onar et al. (2018) & Education in Industry 4.0 Era, Qualitative \\
\hline
\end{tabular}

Total artikel yang relevan untuk bahan kajian literature review adalah 12. Meskipun hanya sedikit, artikel-artikel yang digunakan tersebut berfokus pada manajemen pendidikan dengan bidang garapan pada era 4.0 untuk meningkatkan kualitas pendidikan. Sebagian besar artikel yang dikecualikan dari literature review ini membahas manajemen era 4.0 di industri dan perusahaan pada umumnya. Artikel tersebut mayoritas membahas sistem manajemen dan strategi manajemen dalam peningkatan kualitas manajerial perusahaan dalam meningkatkan profit atau laba perusahaan serta dalam meningkatkan kualitas SDM untuk menangani dan menyelesaikan pekerjaan perusahaan.

Terdapat 12 artikel setelah proses seleksi yang dilakukan. Dua di antaranya diambil dari book chapter yang relevan dalam sistematika literature review ini. Proses pencarian referensi lebih lanjut untuk kajian literature review ini mendukung temuan-temuan yang dibahas sesuai dua pertanyaan literature review yang sudah disiapkan untuk menemukan konsep baru atau kerangka konseptual manajemen pendidikan dalam meningkatkan kualitas pendidikan era 4.0.

Data dikumpulkan menggunakan ekstraksi data, termasuk informasi mengenai ukuran sampel/jumlah informan, desain penelitian, dan metode penelitian yang digunakan. Penyusunan data mengacu pada dua pertanyaan penelitian yang sudah disajikan dalam latar belakang/pendahuluan. Penulis mengatur data yang dikumpulkan untuk mengidentifikasi jawaban yang dibuat dalam literature ini, selanjutnya merancang kategori yang lebih luas dengan membandingkan hasil literature.

Berdasarkan latar belakang teori dan referensi yang sudah disurvei, penulis membuat daftar program bidang manajemen pendidikan untuk mewujudkan SDM unggul era 4.0, lalu mengidentifikasi kompetensi dan strategi yang perlu dilakukan untuk meningkatkan kualitas pendidikan era 4.0, dan membuat kerangka konseptual manajemen pendidikan dalam meningkatkan kualitas pendidikan era 4.0. Tabel 1 menyajikan 12 artikel yang dipilih untuk literature review ini, mencakup berbagai program dalam manajemen pendidikan untuk meningkatkan kualitas pendidikan era 4.0.

\section{HASIL DAN PEMBAHASAN}

\section{Program Manajemen Pendidikan untuk Mewujudkan SDM Unggul Era 4.0}

Revolusi industri 4.0 merupakan sebuah konsep yang pertama kali diperkenalkan oleh ekonom asal Jerman, Profesor Klaus Schwab, dalam bukunya yang berjudul "The Fourth Industrial Revolution" (Hoel \& Mason, 2018, p. 25). Klaus mengungkapkan tahapan revolusi industri yang setiap tahapannya dapat mengubah hidup dancara kerja manusia. Kecanggihan teknologi di era 4.0 berpotensi menggeser peran manusia sebagai sumber daya apabila tidak dibekali dengan skill yang mumpuni (Jandric et al., 2019). Oleh karena itu, dalam meningkatkan peran SDM menghadapi era 4.0, dibutuhkan penguatan dan pengembangan dalam konteks digitalisasi maupun budaya. Revolusi industri 4.0 merupakan sebuah keniscayaan dengan ditandai munculnya Internet of Things (IoT), big data, artificial intelligence, dan cloud computing (Syakdiyah, 2019). 
Dalam menjawab tantangan revolusi 4.0, ada program transformasi 4.0 (Johansson, 2019). Program tersebut ialah program percepatan perubahan di bidang digitalisasi, pengembangan SDM, dan penajaman budaya sebagai persiapan SDM memasuki dan menyambut era industri 4.0 (Kim, 2016). Fokus utama program transformasi 4.0 dalam bidang manajemen pendidikan adalah memberikan berbagai field-study bagi para peserta didik serta program magang di berbagai instansi, baik pendidikan maupun swasta (industri), dengan memberikan target sebagai indikator kesuksesan.

Program manajemen pendidikan melalui transformasi digital ini bertujuan menciptakan kebiasaan disiplin tinggi dan memiliki daya saing tangguh (Kirsch \& Lennon, 2017). Tujuan lain yang relevan adanya program ini adalah menjadikan peserta didik sebagai agen perubahan yang dapat membawa pengaruh positif di lingkungan dan masyarakat. Program transformasi digital bidang manajemen pendidikan yang dapat mewujudkan SDM unggul era 4.0 ini terbagi dalam tiga program percepatan perubahan dalam lembaga pendidikan: (1) transformasi digital, (2) transformasi SDM, dan (3) transformasi budaya (Harususilo, 2019). Percepatan perubahan manajemen pendidikan berkaitan dengan keuangan, kesiswaan, sarana prasarana, pendidik dan tenaga kependidikan, serta kurikulum yang dapat diproses melalui solusi digital. Fokus utama program ini terdiri atas digital campus, digital process, digital facilities, digital services, dan digital learning.

Transformasi SDM ini berkaitan dengan percepatan dalam peningkatan kompetensi SDM pada umumnya (Larsen et al., 2019). Fokus utamanya adalah menjadikan vokasi training dan kewirausahaan sebagai bagian dari kurikulum pendidikan (Lee, 2018). Transformasi budaya berkaitan dengan percepatan penajaman budaya dalam sikap menjalankan pekerjaan dengan pola pikir positif, disiplin, cermat, semangat, tangguh, dan penajaman deradikalisme sehingga menjadi pribadi yang memberikan pengaruh positif pada lingkungan pendidikan.

Implementasi program transformasi digital era 4.0 dapat melibatkan civitas akademika seperti kepala sekolah dan guru di lingkungan sekolah, dan lingkungan perguruan tinggi seperti rektor, dekan, dan mahasiswa dengan para trainer didampingi oleh coach trainer yang ahli dalam bidangnya masing-masing, dan tersertifikasi. Sasaran utama pemanfaatan digital di lingkungan pendidikan adalah semua elemen yang terlibat (Lim et al., 2019). Pemahaman yang mumpuni terkait transformasi digital era 4.0 inilah yang mampu menjawab tantangan perkembangan zaman dan dapat memberi kontribusi nyata menciptakan SDM Indonesia unggul dan daya saing sesuai prinsip "education for all" bahwa pendidikan berkualitas bukan hanya milik kota besar dan masyarakat mampu saja.

Melalui digital distance learning dan mobile apps based ini, diharapkan tujuan pendidikan untuk semua pihak dapat tercapai secara cepat, tepat, terstruktur, serta berkesinambungan. Hal itu dilakukan guna membangun sumber daya manusia (SDM) Indonesia unggul, kreatif, dan inovatif dalam menyongsong era revolusi industri (Lin, 2019). Salah satunya, e-learning, menjadi terobosan dalam meningkatkan akses pendidikan tinggi yang bermutu di seluruh wilayah Indonesia.

Lima program unggulan guna membangun SDM Indonesia unggul menurut Sekretaris Jenderal Kemenristekdikti, Ainun Na'im, dalam Kelana (2019), yaitu: (1) insfrastruktur teknologi informasi dan komunikasi (TIK); (2) perubahan konten kurikulum; (3) sertifikasi kompetensi; (4) kolaborasi industri; dan (5) semangat kewirausahaan. Hal ini sejalan dengan Tarigan (2019) yang menyatakan bahwa ada empat langkah strategis menuju pembangunan SDM Indonesia Unggul yang harus menjadi prioritas utama dalam pembangunan kualitas SDM, antara lain: (1) meningkatkan sistem pendidikan yang baik dan bermutu; (2) penguatan peran agama dalam kehidupan sosial bermasyarakat demi memperkokoh jati diri dan kepribadian bangsa (character building); (3) peningkatan kapasitas SDM melalui berbagai pendidikan dan latihan (diklat), kompetensi, pembinaan; dan (4) pembinaan dan pengembangan masyarakat, terutama generasi muda.

Pembangunan infrastruktur TIK memiliki peran vital dalam upaya mengakselerasi pembangunan Indonesia yang unggul dan mampu bersaing di tingkat global di era revolusi 4.0 (Mao et al., 2019). Pengembangan TIK dalam sebuah lembaga pendidikan ini berkaitan dengan pembelajaran di kelas. Para pendidik dapat merancang sedemikian rupa materi pembelajaran terbaik dengan menggunakan cyber school/university dalam mengembangkan konektivitas melalui e-learning.

Berdasarkan berbagai program yang telah disebutkan, secara umum, dapat disimpulkan bahwa program-program yang dapat dilaksanakan untuk manajemen pendidikan dalam mewujudkan SDM unggul era 4.0 adalah sebagai berikut: (1) perbaikan dan pengembangan keterampilan SDM yang mumpuni; (2) peran pemerintah dalam mengubah metode pembelajaran sesuai dengan kebu- 
tuhan tantangan revolusi 4.0; (3) mengusung pendidikan 4.0; (4) teknologi informasi dan komunikasi untuk pembelajaran di era revolusi industri 4.0; (5) dukungan sarana dan prasarana kecerdasan buatan; (6) solusi lembaga pendidikan yang menghadapi revolusi industri 4.0; (7) revisi kurikulum dengan menambahkan lima kompetensi (kemampuan berpikir kritis, memiliki kreativitas dan kemampuan yang inovatif, kemampuan dan keterampilan berkomunikasi yang baik, kemampuan kerja sama, dan memiliki kepercayaan diri yang tinggi).

Perencanaan pembelajaran ini perlu disinkronkan dengan perubahan konten kurikulum. Mengintegrasikan kemampuan dasar mengenai teknologi, data, dan 'humanity', sama dengan menyiapkan lulusan yang kompeten dan mampu menghadapi tantangan dunia kerja era 4.0 (Mccartney \& Metcalfe, 2018). Selanjutnya, peningkatan kompetensi siswa/mahasiswa melalui pembelajaran perlu di-upgrade sesuai kondisi lapangan, sehingga memerlukan kerja sama dengan lembaga lain untuk meningkatkan relevansi kurikulum sesuai kebutuhan era 4.0 (Meshkat et al., 2018). Kerja sama yang erat antara lembaga pendidikan dengan dunia kerja bertujuan mengisi ruang perbedaan antara teori dan praktik. Kompetensi dan kreativitas lulusan ini yang menjadi fokus pengembangan SDM di sekolah maupun perguruan tinggi. Tenaga kerja yang profesional dan terampil sesuai tuntutan/ kebutuhan pasar kerja merupakan keunggulan suatu bangsa dalam menghadapi persaingan global.

Tuntutan kompetensi era 4.0 ini tidaklah menghasilkan lulusan yang siap untuk kerja sesuai perkembangan dan kebutuhan, melainkan juga dapat meningkatkan kreativitas dan jiwa kewirausahaan. Kompetensi dalam membuka lapangan kerja merupakan hasil inovasi pembelajaran yang penting dalam menciptakan industri kreatif di era digital.

\section{Kerangka Konseptual Manajemen Pendidikan dalam Meningkatkan Kualitas Pendidikan di Era 4.0}

Bagian ini membahas bagaimana manajemen pendidikan di era 4.0 dapat meningkatkan kualitas pendidikan. Artikel-artikel yang dipilih untuk menjawab pertanyaan literature review yang kedua ini mendiskusikan berbagai konsep yang disusun untuk mengelola dan mengatur pendidikan sesuai kebutuhan dan perkembangan era.

Salah satu perubahan dalam manajemen pendidikan yang terbentuk adalah dengan perbaikan sumber daya manusia (SDM) (Husnurofik et al., 2019). Konsep perubahan inilah yang nantinya dapat menciptakan sebuah sistem perubahan dan konseptual yang perlu dilakukan oleh sumber daya manusia yang berkecimpung di dunia pendidikan dalam menghadapi era 4.0.

Manajemen pendidikan merupakan rangkaian prencanaan, pelaksanaan, pengawasan, pembiayaan dan pengevaluasian dengan memanfaatkan education system yang tersedia, baik sumber daya manusia maupun sumber daya yang lain. Secara umum, manajemen pendidikan memiliki garapan terkait dengan kesiswaan, kurikulum, keuangan, sarana-prasarana, pendidikan dan tenaga kependidikan, serta hubungan dengan masyarakat.

Penyelenggaraan pendidikan yang bermutu dapat menghasilkan efisiensi pendidikan. Hal ini ditunjukkan ketika proses pendidikan dikelilingi lingkungan dan faktor yang mendukung (Zhuang et al., 2019), begitu juga ketika mampu mempersiapkan diri untuk menghadapi tantangan dan perubahan kebutuhan negara secara ekonomi dan sosial (Faisal \& Martin, 2019). Pelaksanaan pendidikan era 4.0 yang dikelola dengan baik tentunya akan menghasilkan kualitas baik (Ahad et al., 2018).

Hal yang paling fundamental dalam manajemen pendidikan adalah mengubah pola pikir (Baltaru \& Soysal, 2018). Selanjutnya, lembaga pendidikan, baik sekolah maupun perguruan tinggi, mengasah, mengembangkan, dan mengubah model sistem manajemen (Chen et al., 2019). Begitu juga memberikan fasilitas yang memadai sesuai kebutuhan yang dapat digunakan untuk memanfaatkan teknologi terkini dalam sistem manajemen dan pembelajaran (Chung, 2016).

Konsep manajemen pendidikan era 4.0 yang penting untuk diperhatikan oleh lembaga pendidikan adalah adanya kompetensi, keterampilan, komunikasi, dan networking. Hal senada juga disampaikan oleh Hammond (2016) bahwa untuk mengembangkan sistem manajemen pendidikan, perlu adanya dua hal, yaitu internationalization dan global competitiveness. Pada era 4.0 saat ini, perlu ditingkatkan daya saing global, baik di tingkat nasional maupun internasional. Tantangan untuk pendidikan ada dua hal, yaitu lulusan harus dilengkapi dengan pengetahuan dan keterampilan yang dibutuhkan untuk bersaing dalam ekonomi pengetahuan yang semakin mengglobal. 
Kompetisi era 4.0 dapat dijadikan sebagai bahan kajian untuk dapat direspon secara strategis terhadap peningkatan persaingan global, melalui penelitian yang semakin inovatif dan reputasi internasional. Strategi yang paling umum untuk merespon kemajuan revolusi industri 4.0 adalah dengan investasi SDM. Peningkatan kualitas SDM menjadi perhatian penting dalam menghadapi era globalisasi (Mahmudah, 2016), terlebih dalam suasana kritis multidimensi, seluruh civitas akademika membutuhkan dukungan berbagai pihak untuk menghadapi persaingan bebas.

Ketika SDM sudah unggul dan memiliki keterampilan mumpuni dalam persaingan ketat era 4.0, selanjutnya adalah menggunakan operasional teknologi dan informasi melalui big data. Big data adalah sistem teknologi yang diperkenalkan untuk menanggulangi "ledakan informasi", seiring dengan pertumbuhan ekosistem pengguna mobile dan internet yang semakin tinggi. Pertumbuhan tersebut sangat mempengaruhi perkembangan volume serta jenis data yang terus meningkat secara signifikan di dunia maya. Big data merupakan salah satu strategi yang harus dikuasai untuk digunakan seorang pendidik dalam meneliti dan menganalisa kemampuan peserta didiknya dengan mudah, tidak hanya individual, namun dapat dilakukan secara kolektif satu kelas maupun lembaga (Rungfamai, 2018). Big data dapat dimanfaatkan pula dengan menggunakan scele dan siak-ng, yang merupakan penerapan $e$-learning untuk mempermudah pengambilan dan pengumpulan data.

Lain hal dengan manajemen kurikulum era 4.0, mengahadapi era 4.0 memang harus sigap menyesuaikan diri dengan berbagai perkembangan. Perlu adanya reformasi, peningkatan kapasitas, profesionalisme, kurikulum yang dinamis, sarana-prasarana andal, dan teknologi pembelajaran mutakhir di era 4.0. Hal itu menjadi keharusan bagi seorang pendidik yang dapat membentuk generasi yang kreatif, inovatif, dan kompetitif. Salah satu hal yang dapat dicapai adalah dengan mengoptimalkan penggunaan teknologi sebagai alat bantu pendidikan, yang diharapkan dapat menghasilkan output yang dapat mengikuti atau mengubah zaman menjadi lebih baik. Indonesia pun perlu meningkatkan kualitas lulusan sesuai dunia kerja dan tuntutan teknologi digital. Kerangka konseptual manajemen pendidikan dalam meningkatkan kualitas pendidikan era 4.0 disajikan pada Gambar 2 .

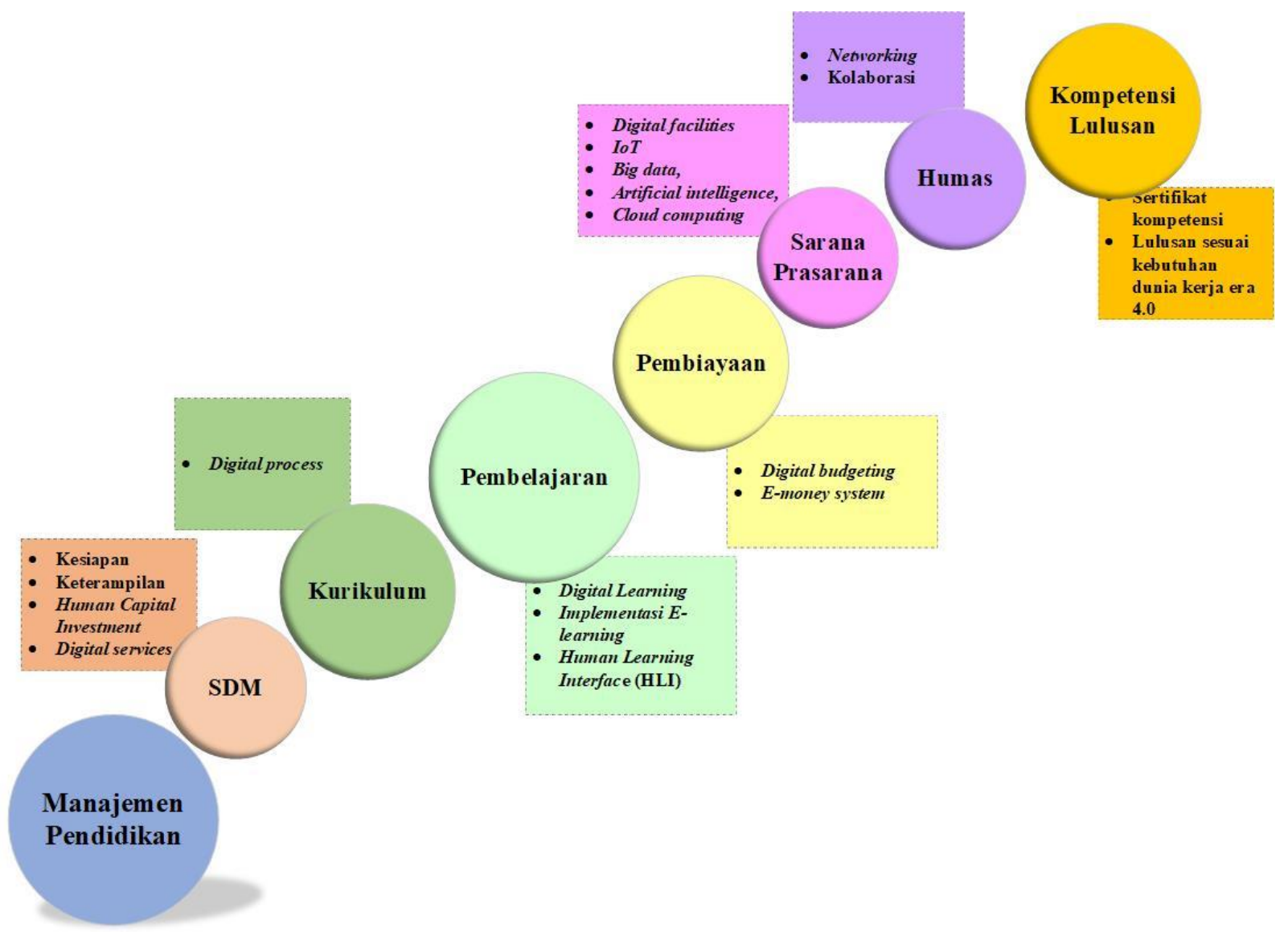

Gambar 2. Kerangka Konseptual Manajemen Pendidikan dalam Meningkatkan Kualitas Era 4.0 
Gambar 2 merupakan temuan dari literature review. Proses manajemen pendidikan untuk meningkatkan kualitas pendidikan era 4.0 dapat dilihat dari tujuh komponen yang meliputi SDM, kurikulum, pembelajaran, pembiayaan, sarana dan prasarana, humas, dan kompetensi lulusan.

SDM di era 4.0 menekankan pada kesiapan, keterampilan, investasi (human capital investment), dan digital service. Hal terpenting dari pengembangan SDM adalah adanya investasi yang memadai dan mencukupi untuk dapat menjadikan SDM lebih unggul dan menjunjung profesionalitas tanpa batas dalam bekerja, serta dalam menghadapi dan mengoperasikan peralatan sesuai dengan kebutuhan dunia kerja.

Kurikulum era 4.0 lembaga pendidikan fokus pada digital process. Kurikululm dapat didesain sesuai dengan kebutuhan keterampilan dan kompetensi dari lulusan. Digital process menitikberatkan pada proses yang dilakukan mulai dari penyusunan, pemanfaatan, pelaksanaan, hingga pengevaluasian dari kurikulum berbentuk digital, sehingga konektivitas antara apa yang diharapkan oleh sekolah dengan kebutuhan tantangan bisa saling berkesinambungan tanpa ada miss match antara lembaga pendidikan dengan tantangan revolusi industri 4.0.

Pembelajaran yang perlu ditingkatkan dalam menghadapi perkembangan era 4.0 adalah persiapan pembelajaran melalui digital learning, implementasi e-learning, dan yang paling utama adalah human learning interface (HLI). Koper (2014) memperkenalkan konsep HLI, yaitu seperangkat mekanisme interaksi yang diekspos pada orang-orang di luar pembelajaran yang dapat digunakan untuk mengontrol, memberikan stimulasi, dan memfasilitasi proses belajar mengajar.

Pembiayaan di lembaga pendidikan era 4.0 perlu ditekankan pada penggunaan sistem keuangan yang tersistem, seperti digital budgeting dan e-money system, yaitu sistem yang dirancang untuk segala bentuk aktivitas pembayaran maupun pembelian versi digital tanpa adanya bentuk fisik uang. Efektivitas penggunaan ini terlihat ketika layanan didunia global sudah menuntun dan menanti dengan menggunakan sistem yang canggih tanpa harus manual dan konvensional.

Sarana dan prasarana yang perlu ditingkatkan untuk mencapai titik kualitas pendidikan era 4.0 adalah dengan digital facilities, IoT, Big data, Artificial Intelligence, dan Cloud Computing. Hubungan masyarakat (humas) merupakan peran yang sentral untuk pengembangan lembaga pendidikan serta membantu sekolah dalam memantapkan visi misi sesuai dengan tujuan lembaga pendidikan. Humas menjadi penting karena adanya networking dan kolaborasi.

Kompetensi lulusan merupakan komponen yang perlu diperhatikan untuk memastikan bahwa lulusan lembaga pendidikan memiliki kualitas pengetahuan dan keterampilan yang unggul, yang dibarengi dengan karakter yang baik. Kompetensi lulusan ini adalah salah satu kajian yang harus diperhatikan dalam sebuah pendidikan. Tanpa adanya output yang baik dan mampu bersaing pada perubahan era, maka pendidikan bisa dikatakan kurang berkualitas.

\section{SIMPULAN}

Perubahan era yang sekarang sudah memasuki revolusi industri 4.0 merupakan hal yang wajar. Kewajaran tersebut memerlukan perhatian yang lebih untuk dapat digunakan dan dimanfaatkan dalam keunggulan bersaing melalui pendidikan. Poin penting dari keterlaksanaan pendidikan adalah adanya manajemen yang baik. Bidang-bidang garapan yang menjadi tumpuan penting dari pelaksanaan pendidikan inilah yang menjadi perhatian utama. Artikel ini telah menemukan bahwa kajian utama dari manajemen pendidikan era 4.0 dalam keterlibatannya untuk meningkatkan kualitas pendidikan, meliputi: SDM, kurikulum, pembelajaran, pembiayaan, sarana prasarana, humas, dan kompetensi lulusan.

Masing-masing bidang garapan tersebut memiliki peranan yang penting satu dengan yang lain. Pelaksanaan yang kolaboratif diharapkan dapat menjadikan setiap bidang garapan mampu memberi kontribusi nyata, sehingga lembaga pendidikan tidak sekedar melaksanakan pendidikan berdasarkan peraturan perundang-undangan saja, melainkan juga memiliki semangat ruh yang mampu mengembangkan dan menjembatani antara pola pikir dengan perubahan perkembangan era 4.0.

Indikator keberhasilan dari masing-masing bidang garapan memang belum terukur. Satu hal yang pasti, ketika lembaga pendidikan mampu menerapkan transformasi digital di setiap aktivitas pendidikan, maka hal itulah yang akan menjadi dasar bahwa lembaga pendidikan mampu untuk bersaing dan menghadapi tantangan sesuai kebutuhan revolusi industri 4.0. 


\section{DAFTAR PUSTAKA}

Ahad, M. A., Tripathi, G., \& Agarwal, P. (2018). Learning analytics for IoE based educational model using deep learning techniques: Architecture, challenges and applications. Smart Learning Environments, 5(7), 2-16. https://doi.org/10.1186/s40561-018-0057-y

Baltaru, R., \& Soysal, Y. (2018). Administrators in higher education: Organizational expansion in a transforming institution. Higher Education, 3(4), 213-229. https://doi.org/10.1007/s10734017-0204-3

Chen, Y., Daamen, T. A., Heurkens, E. W. T. M., \& Verheul, W. J. (2019). Interdisciplinary and experiential learning in urban development management education. International Journal of Technology and Design Education, 3(4), 54-61. https://doi.org/10.1007/s10798-01909541-5

Chung, P. (2016). Influence of problem-based learning strategy on enhancing student's industrial oriented competences learned: An action research on learning weblog analysis. International Journal of Technology and Design Education, 26(4), 285-307. https://doi.org/10.1007/s10798-015-9306-3

Cohen, Y., Faccio, M., \& Pilati, F. (2019). Design and management of digital manufacturing and assembly systems in the industry 4.0 era. The International Journal of Advanced Manufacturing Technology, 3(105), 3565-3577. https://doi.org/10.1007/s00170-01904595-0

Faisal, F., \& Martin, S. N. (2019). Science education in Indonesia: Past, present, and future. Asia Pacific Journal of Education, 5(4), 2-29. https://doi.org/10.1186/s41029-019-0032-0

Gleason, N. W. (2019). Singapore's higher education systems in the era of the fourth industrial revolution: Preparing lifelong learners. In N. W. Gleason (Ed.), Higher education in the era of the fourth industrial revolution (pp. 145-169). Palgrave Macmillan. https://doi.org/10.1007/978-981-13-0194-0

Grant, M. J., \& Booth, A. (2009). A typology of reviews: An analysis of 14 review types and associated methodologies. Health Information and Libraries Journal, 26(2), 91-108. https://doi.org/10.1111/j.1471-1842.2009.00848.x

Hammond, C. D. (2016). Internationalization, nationalism, and global competitiveness: A comparison of approaches to higher education in China and Japan. Asia Pacific Education Review, 17(4), 555-566. https://doi.org/10.1007/s12564-016-9459-0

Harususilo, Y. (2019). Mewujudkan SDM unggul lewat program "Transformasi 4.0." Kompas. Retrieved from https://edukasi.kompas.com/read/2019/11/15/21055981/mewujudkan-sdmunggul-lewat-program-transformasi-40?page $=$ all

Hazelkorn, E. (2018). The accountability and transparency agenda: Emerging issues in the global era. European Higher Education Area: The Impact of Past and Future Policies, 5(4), 423439. https://doi.org/10.1007/978-3-319-77407-7

Hoel, T., \& Mason, J. (2018). Standards for smart education - towards a development framework. Smart Learning Environments, 5(4), 3. https://doi.org/10.1186/s40561-018-0052-3

Husnurofik, Z., Mahmudah, F. N., \& Usman, H. (2019). A systematic review on sustainable human resource management: A framework for managing training in the Indonesian police force. Advances in Social Science, Education and Humanities Research, 317(1), 160-164. https://doi.org/10.2991/iconprocs-19.2019.33

Jandric, P., Ryberg, T., Knox, J., Lackovic, N., Hayes, S., Suoranta, J., Smith, M., ... Gibbons, A. (2019). Postdigital dialogue. Postdigital Science and Education, 1(2), 163-189. https://doi.org/10.1007/s42438-018-0011-x 
Johansson, S. (2019). Teacher specialization and student perceived instructional quality: What are the relationships to student reading achievement ? Educational Assessment, Evaluation and Accountability, 31(3), 177-200. https://doi.org/10.1007/s11092-019-09297-5

Kelana, N. S. (2019). Berikut lima program unggulan guna membangun SDM unggul. Siedoo. Retrieved from https://siedoo.com/berita-17957-berikut-lima-program-unggulan-gunamembangun-sdm-unggul/

Khlaif, Z. N., \& Farid, S. (2018). Transforming learning for the smart learning paradigm: Lessons learned from the Palestinian initiative. Smart Learning Environments, 5(12), 2-21. https://doi.org/10.1186/s40561-018-0059-9

Kim, J. (2016). Development of a global lifelong learning index for future education. Asia Pacific Education Review, 3(2), 14-20. https://doi.org/10.1007/s12564-016-9445-6

Kirsch, I., \& Lennon, M. L. (2017). PIAAC: A new design for a new era. Large-scale Assessments in Education, 5(4), 11. https://doi.org/10.1186/s40536-017-0046-6

Koper, R. (2014). Conditions for effective smart learning environments. Smart Learning Environments, 1, 5. https://doi.org/10.1186/s40561-014-0005-4

Larsen, C. M., Terkelsen, A. S., Carlsen, A. F., \& Kristensen, H. K. (2019). Methods for teaching evidence-based practice: A scoping review. BMC Medical Education, 19(4), 259. https://doi.org/10.1186/s12909-019-1681-0

Lase, D. (2019). Pendidikan di era revolusi industri 4.0. SUNDERMANN: Jurnal Ilmiah Teologi, Pendidikan, Sains, Humaniora Dan Kebudayaan, 12(2), 28-43. https://doi.org/10.36588/sundermann.v1i1.18

Lee, K. (2018). Everyone already has their community beyond the screen: Reconceptualizing online learning and expanding boundaries. Educational Technology Research and Development, 66(5), 1255-1268. https://doi.org/10.1007/s11423-018-9613-y

Lim, C. P., Wang, T., \& Graham, C. (2019). Driving, sustaining and scaling up blended learning practices in higher education institutions: A proposed framework. Innovation and Education, 3(4), 1-12. https://doi.org/10.1186/s42862-019-0002-0

Lin, J. (2019). From a lecturer to a researcher: A three-stage process of science teachers' professional development in mainland China. Asia-Pacific Science Education, 7(5), 11. https://doi.org/10.1186/s41029-019-0042-y

Mahmudah, F. N. (2016). Keefektifan human capital investment pendidikan tenaga kependidikan di Universitas Negeri Yogyakarta. Jurnal Akuntabilitas Manajemen Pendidikan, 4(1), 7787. https://doi.org/10.21831/amp.v4i1.8201

Mao, J., Ifenthaler, D., Fujimoto, T., Garavaglia, A., \& Rossi, P. G. (2019). National policies and educational technology: A synopsis of trends and perspectives from five countries. TechTrends, 63(5), 284-293. https://doi.org/10.1007/s11528-019-00396-0

Mccartney, D. M., \& Metcalfe, A. S. (2018). Corporatization of higher education through internationalization: The emergence of pathway colleges in Canada. Tertiary Education and Management, 13(4), 1-15. https://doi.org/10.1080/13583883.2018.1439997

Meshkat, N., Teklu, S., \& Hunchak, C. (2018). Design and Implementation of a postgraduate curriculum to support Ethiopia's first emergency medicine residency training program: The Toronto Addis Ababa Academic Collaboration in Emergency Medicine (TAAAC-EM). BMC Medical Education, 18(3), 1-8. https://doi.org/10.1186/s12909-018-1140-3

Onar, S. C., Ustundag, A., Kadaifci, Ç., \& Oztaysi, B. (2018). The changing role of engineering education in industry 4.0 era. In A. Ustundag \& E. Cevikcan (Eds.), Industry 4.0: Managing the digital transformation, springer series in advanced manufacturing (pp. 137151). Springer. 
Robinson, P., \& Lowe, J. (2015). Literature reviews vs systematic reviews. Public Health Association of Australia, 39(2), 103. https://doi.org/10.1111/1753-6405.12393

Rungfamai, K. (2018). State, university, and society: Higher educational development and university functions in shaping modern Thailand. Higher Education, 5(6), 75-80. https://doi.org/10.1007/s10734-018-0335-1

Seretny, M., \& Gaur, D. (2020). The model of sustainable marketing as a responsible approach to marketing in the era of industry 4.0. Sustainable Development and Social Responsibility, 1(6), 283-289. https://doi.org/10.1007/978-3-030-32922-8

Syakdiyah, A. (2019). Active learner strategies in era of disruption: A literature review. International Conference on Progressive Civil Society, 317(1), 165-168. https://doi.org/10.2991/iconprocs-19.2019.34

Tarigan, E. (2019). Langkah strategis menuju pembangunan SDM Indonesia unggul. Retrieved from https://www.ui.ac.id/langkah-strategis-menuju-pembangunan-sdm-indonesia-unggul/

Verner, I., Cuperman, D., Romm, T., Reitman, M., Chong, S. K., \& Gong, Z. (2018). Intelligent robotics in high school: An educational paradigm for the industry 4.0 era. Intelligent Robotics in High School, 1(5), 824-832. https://doi.org/10.1007/978-3-030-11932-4

Zhuang, T., Cheung, A. C. K., Lau, W. W. F., \& Tang, Y. (2019). Development and validation of an instrument to measure STEM undergraduate students' comprehensive educational process. Front. Educ. China, 14(4), 575-611. https://doi.org/10.1007/s11516-019-0028-2 